\title{
A STUDY OF SADNESS METAPHOR IN LI BAI'S POETRY AND ITS ENGLISH TRANSLATION FROM THE PERSPECTIVE OF IMAGE SCHEMA
}

\author{
Huang, Shanshan, \\ Wang, Feng $i$ \\ School of Foreign Studies, \\ Yangtze University, \\ Hubei Province, 434023, \\ P. R. China
}

\begin{abstract}
:
Li Bai, a great poet in the Tang Dynasty, is known for his romantic poetic style, but sadness metaphor is not rare in his poems. Therefore, this paper takes sadness metaphor in Li's poetry as the object of study to explore its metaphorical meanings from the perspective of cognitive linguistics. From that, we can find that image schema is frequently used as the source domain to describe the abstract sadness. Based on this, the authors focus on the relationship between sadness metaphor and image schema and then discuss the English translation of sadness metaphor, trying to find out the characteristics and effective strategies of translating sadness metaphor in Li Bai's poems.
\end{abstract}

Keywords: Li Bai's poetry; sadness metaphor; cognitive linguistics; image schema; characteristics; strategies

\section{Introduction}

In classical Chinese poetry, poets usually write poems to express their happiness, sorrow, love and so on, so poetry is the reflection of poets' emotions. Tang poetry represents the highest level of classical Chinese poetry and there are a large number of excellent poets in the Tang Dynasty. During that period, the poet Li Bai stands out for his poetic talent and his poems have been widely read and highly appreciated through the generations. Likewise, the works of Li Bai are full of emotions and the poet likes expressing his emotions by metaphors. Such metaphorical expressions of emotions are called emotion metaphors which can achieve a good artistic effect but increase readers' difficulties in comprehension at the same time. Thus, emotion metaphor translation is the focus and difficulty in poetry translation. Previous studies on metaphor are mostly confined to the field of rhetoric, and with the further development of research, the cognitive nature of metaphor has been mentioned: metaphor is more than a matter of language; it's a matter of thinking. Based on Conceptual Metaphor Theory and

i Correspondence: email wangfeng@yangtzeu.edu.cn 
Image Schema Theory in the framework of cognitive linguistics, the study first makes a detailed analysis of sadness metaphors in Li Bai's poetry and then pays more attention to the English translation of sadness metaphors. The authors selected generally acceptable English translations of metrical and free styles respectively to conduct a comparative study. The findings show that: sensory image schemas and the SCALE schema are often mapped onto Li Bai's experience of sadness to metaphorically conceptualize the latter. These two types of image schemas are basically reproduced in translating with the strategies of retaining the original metaphor, converting the original metaphor and paraphrasing the original metaphor.

\section{Previous Studies on Emotion Metaphor Translation}

As a psychological phenomenon, emotion is too abstract, so we usually express it in vivid language. In many cases, metaphorical expressions can be used to conceptualize certain emotions and emotion metaphors appear. When Lakoff and Johnson introduced orientational metaphors in Metaphors We Live By, they took the metaphors "HAPPY IS UP" and "SAD IS DOWN" as examples (1980: 15). They also took the metaphor "LOVE IS A JOURNEY" as an example to demonstrate the idea: connections between metaphors are more likely to involve coherence than consistency (1980: 44-45). It's obvious that emotion metaphor is an important part of conceptual metaphor. After that, another representative Kövecses (2000) tried to find a number of metaphorical source domains that characterize basic emotions like happiness, sadness, anger, fear and love. Maybe inspired from that, some scholars (Zhang Rong, 2010; $\mathrm{Wu}$ Ni, 2013; Zhang Chenchen, Cao Jing, 2017) conducted studies on the English translation of a certain emotion metaphor in a literary work. And there are also scholars whose researches are done from macroscopic perspective. More specifically, Yue Haoping and Liao Shijun (2009) analyzed emotion metaphor's cognitive universality and particularity between Chinese and English, and then put forward translation strategies to achieve equivalence in cognition. Different from the above studies, Feng Quangong and Li Lin (2017) focused on emotion metaphors in classical Chinese poems and their English translations. Based on the previous achievements, we can see that emotion metaphor has been paid attention to. Emotion metaphor translation is a big topic, so some scholars explore basic emotion metaphors in novels or classical Chinese poetry. Because emotion metaphors like fear, anger and love have been discussed, we can take other basic emotion metaphors as the object of future study. Besides, there are so many excellent Chinese poems which can be used for analysis. After a comprehensive consideration, the authors conducted a study on sadness metaphor in Li Bai's poetry and its English translation from the perspective of cognitive linguistics. And we adopted different translations for comparison of source texts widely used in previous researches.

\section{About the Translations}

There are various English versions of Li Bai's poems given by translators from the metrical verse school and the free verse school. On the one hand, both metrical translators and free 
verse translators almost agree with the view of translating poetry into poetry (Wang Feng, 2015: 86). On the other hand, there are different features between these two styles of translation. In metrical translations, rhythm is considered as the soul of poetry so metrical translators try their best to reproduce the beauty in sound. And in free verse translations, the charm of poetry may be preserved but rhyme is neglected. Thus, it's necessary to discuss the metrical verse school and the free verse school when we study the English translation of $\mathrm{Li}$ Bai's poems. In this paper, the chosen English translations include two translations by $\mathrm{Xu}$ Yuanchong and Zhao Yanchun who are representatives of the metrical verse school, and two translations by Shigeyoshi Obata and Rewi Alley who are representatives of the free verse school.

\section{Conceptual Metaphor Theory and Image Schema Theory}

Conceptual metaphor and image schema are two main modes employed to perceive the world, and image schemas play an important role in understanding metaphors, so both Conceptual Metaphor Theory and Image Schema Theory will be applied as theoretical guidance.

\subsection{Conceptual Metaphor Theory}

Conceptual Metaphor Theory is first put forward by George Lakoff and Mark Johnson (1980) in their masterpiece Metaphors We Live By. Metaphor, in this theory, consists of two conceptual domains: the source domain and the target domain. The target domain is the abstract domain to be conceptualized, and the more concrete source domain is used to conceptualize the abstract domain. It's mappings from the source domain to the target domain that give rise to metaphorical expressions. That is to say, certain characteristics or properties possessed by the source domain are mapped onto the target domain, making a set of correspondences. According to definitions of conceptual metaphor given by many scholars, we can conclude that conceptual metaphor is a process by which the target domain of experience is structured in terms of the source domain of experience after comparison or judgment, and the crossdomain mapping between the target domain and the source domain is the nature of conceptual metaphor.

\subsection{Image Schema Theory}

In 1980, Lakoff and Johnson mentioned the concept of image schema when they talked about Conceptual Metaphor Theory in Metaphors We Live By. Later, the concept of image schema is put forward. According to Johnson (1987), image schemas originate from human's embodied experiences, and our conception of image schemas plays an important role in explaining the embodied origins of our understanding. Since then, many scholars began to pay attention to image schema. There are different opinions about the definition of image schema, but briefly, image schemas are recurring patterns of our sensory-motor experience which can be used to structure abstract concepts. Besides, the classification of image schemas is also an important aspect of Image Schema Theory. The CONTAINER Schema, the LINK Schema, the SOURCE- 
PATH-GOAL Schema and the UP-DOWN Schema are regarded as common image schemas (Li Fuyin, 2008: 191).

\section{Sadness Metaphors and Image Schemas}

Throughout his life, Li Bai has travelled all over the country, and numerous poems have been created on the journey. Due to the experience of being a wanderer, many poems are related to sadness. However, the poet doesn't like expressing his feelings directly, so metaphorical expressions can be seen in his works which are called sadness metaphors. Image schemas like sensory image schemas, the SCALE schema, the DOWN schema and the CONTAINER schema can be used as the source domains to describe the abstract sadness. The authors will discuss sensory image schemas and the SCALE schema in detail because of their frequency.

\subsection{Sadness Metaphors and Sensory Image Schemas}

Sensory image schemas are often mapped onto Li Bai's experience of sadness to metaphorically conceptualize the latter. In the category of sensory image schemas, PAIN, COLD and BITTER can be applied to explain the sadness metaphors in Li Bai's poems.

\subsubsection{SADNESS IS PAIN}

In Li Bai's poems, the human organ “intestine (肠)" is often used to conceptualize the abstract emotion of sadness in a metaphorical manner. More specifically, the poet compares the bitterness of missing to one's intestine cut off (肠断). Thus, the specific pain can be mapped onto the abstract sadness. Such metaphorical expressions can be found in poems like “Thoughts in Spring” (春思), “Ballad of Complaint” (怨歌行), “Songs of the Southern Girls” ( 越女词) and so on. We can see the conceptual metaphors in these poems exist in the form of the source domain. Next, let's take an example of “断肠” in “Thoughts in Spring" and discuss its translations by different translators.

(1) 当君怀归日, 是妾断肠时。

Xu: When you think of your home on your part,

Already broken is my heart.

Zhao: When you are in nostalgia drowned,

I've been aching for you, spell-bound.

Obata: Even now while my longing heart is breaking,

Are you thinking, my dear, of coming back to me?

Alley: when you ${ }^{2}$ begin to think of me,

I am heartbroken;

${ }^{2}$ The husband was a soldier in the Yen region.

As a masterpiece of Li Bai's boudoir-plaint poetry (闺怨诗), “Thoughts in Spring” expresses a wife's longing for her husband, a soldier in the distance. Her longing for him just grew as time went by, so when her husband thought of her, she had already been heartbroken. 
To show the bitterness of the wife's yearning, the conceptual metaphor "SADNESS IS PAIN" is adopted by the poet. In this conceptual metaphor, the sensory image schema PAIN serves as the source domain, while the abstract concept "SADNESS" is regarded as the target domain, indicating being in sadness is being in pain. Having observed the above translations, we can see that in translating the metaphor, all the translators render the source domain into English. It's worth noting that there is one thing in common among the translations that the metaphorical expression “断肠” in the source language is converted to "heartbroken (心碎)" in the target language. In Chinese, “断肠” is preferred to express sadness, while in English, the metaphorical expression "heartbroken" is always used. It's obvious that there's a difference in the source domain between the Chinese culture and the foreign culture. In this way, the translators can't retain the original source domain in translation or translate it directly, but they can convert the original source domain to the English one which has the same metaphorical concept.

\subsubsection{SADNESS IS COLD}

In real life, when we stay in a cold environment, our body temperature will drop. That is quite similar to the fact when we experience a state of sadness, our body temperature will come down because of some physiological reasons. This kind of metaphorical conceptualization of sadness based on the COLD schema can help us better grasp what is going to be expressed. In Li Bai's poetry, the word “寒” or “凉” is not only used to describe the characteristics of the surroundings but also used to indicate a state of sadness. Such metaphorical expressions can be found in poems like "Ascending Xinping Tower" (登新平楼), “Ascending the Western Tower of Jinling" (金陵城西楼月下吟), “Ascending the North Tower one Autumn Day" (秋登 宣城谢朓北楼) and so on. We can see the conceptual metaphors in these poems exist in the form of the source domain. Next, let's take an example of "寒波" in "Ascending Xinping Tower" and discuss its translations by different translators.

\section{(2) 天长落日远, 水净寒波流。}

Zhao: The sun sets to the skyline vast;

The river cold and calm flows past.

Xu: The sky is vast, the setting sun is far;

The water clear, the waves much colder are.

Obata: The sun has set far beyond heaven's immensity;

The unsullied waters flow on in bleak undulation.

Alley: now it seems that the day is long, and sunset far away; looking down I see waves that make me feel cold,

The poem "Ascending Xinping Tower" describes what the poet saw when he ascended the tower to look far into the distance on an autumn day. Poetic imagery like “落日”, “寒波”, “秦云” and so on in the poem create an atmosphere of sadness. To show the depression of the poet, the conceptual metaphor "SADNESS IS COLD" is used in the verse line here. In this conceptual metaphor, the sensory image schema COLD serves as the source domain, while 
the abstract concept "SADNESS" is regarded as the target domain, indicating being sad is being cold. In translating the metaphor, all the translators translate the source domain. However, when they render the source domain into English, there are some differences in their translations: first, $\mathrm{Xu}$ is the only one to adopt the comparative form of the word "cold" to modify "the waves", which implies that the flowing water is much colder than usual probably because of the low mood of the poet; Obata uses the word "bleak" to modify" the unsullied waters", which may seem strange but emphasizes the depression of the poet; Zhao puts the word "cold" behind "the river" for rhyme, suggesting the low temperature of the flowing water; in Alley's translation, it's the flowing water that makes the poet feel cold. On the one hand, the water temperature in autumn is low. On the other hand, the low mood makes the poet feel quite cold. The flowing water and the poet's feeling are connected based on the similar feature between them. To sum up, the original imagery "寒波” is converted in translations more or less. As we all know, classical Chinese poetry is characterized by its rich imagery which is always used to indicate the men's emotions. This knowledge is more familiar to the source language reader than the target language reader, so the translators above tend to narrow the gap between the translation and the target language reader by conversion.

\subsubsection{SADNESS IS BITTER}

Apart from the above sensory image schemas, the sensory image schema BITTER should also be paid attention to. In Chinese, the taste sense "bitter" is frequently used to conceptualize the abstract emotion of sadness in a metaphorical manner. Such metaphorical expressions can be found in Li Bai's poems such as “Guanshan Yue” (关山月)，“Pavilion Laolao” (劳劳亭), “Ballad of Grief" (怨歌行) and so on. We can see the conceptual metaphors in these poems exist in the form of the source domain. Next, let's take an example of “苦颜” in “Guanshan Yue" and discuss its translations by different translators.

\section{(3) 戌客望边邑，思归多苦颜。}

Zhao: Hardship drives all the soldiers mad;

Nostalgia drowns their faces sad.

Xu: Guards watch the scene of borderland,

Thinking of home, with wistful eyes.

Obata: The warriors watch the skies of the borderland,

And many faces are sad with thoughts of home.

Alley: a frontier soldier looks dully over the waste,

his face full of sadness as he thinks of her at home.

The poem "Guanshan Yue" respectively describes the frontier landscape, the cruel war and border guards' longing to return home. Although these soldiers want to go home, they have to take the responsibility of protecting the national border and stay there year in and year out with homesickness. To show the sadness of the soldiers, the conceptual metaphor "SADNESS IS BITTER" is used in the verse line here. In this conceptual metaphor, the sensory image schema BITTER serves as the source domain, while the abstract concept "SADNESS" is 
regarded as the target domain, indicating the taste of sadness is bitter. From the above translations, we can find that although the original conceptual metaphor exists in the form of the source domain, all the translators translate the target domain. Why do these translators decide to render the target domain instead of the source domain? For Chinese people, “愁 (distressed)” and “苦 (bitter)” are often intertwined such as “愁眉苦脸” or “愁苦”, so when the word “苦” is mentioned, Chinese people can associate “愁” immediately, but foreign people can hardly do that. Based on this fact, the translators tend to explain the metaphorical concept of the word “苦颜” to the target language reader. In addition, there are some slight differences among them: Zhao puts the word "sad" behind "faces" for rhyme, and Obata translates the imagery “苦颜” into a sentence because he doesn't have to focus on rhyme. Likewise, in Alley's translation, “苦颜” is translated into a long phrase without considering rhyme. Last, $\mathrm{Xu}$ 's translation is different from all the others because he converts the original imagery for rhyme. More specifically, the imagery “苦颜” is changed into “渴望的眼神 (wistful eyes)", but the metaphoric effect is also achieved.

\subsection{Sadness Metaphor and the SCALE Schema}

The SCALE schema allows the emotion to be measured through a structure with the three dimensions, namely more, less or the same. This structure induces a cross-domain understanding due to the great difficulty in measuring it directly. By resorting to metaphor, a conceptualizing tool, with which we can understand a non-physical or abstract domain in terms of a physical or concrete domain, it is relatively easy to quantify the abstract emotion. In Chinese, things like “丝 (silk)" and “水 (water)" are often used to express people's sadness and we have such metaphorical expressions as “三千烦恼丝” and “举杯消愁愁更愁, 抽刀断 水水更流”. In Li Bai's poetry, “水” is favored by the poet to measure the object emotion such as “请君试问东流水, 别意与之谁短长” in “Farewell at a Tavern in Jinling” (金陵酒肆留别), “ 思君若汶水” in “To Tu Fu from Shaqiu Town” (沙丘城下寄杜甫), “黄河若不断, 白首长相思” in “Seeing Off Wei Wan Back to Kinghouse” (送王屋山人魏万还王屋) and so on. The metaphorical expressions mentioned here exist in the form of the source domain and the target domain, and we will take an example of sadness metaphor in "Farewell at a Tavern in Jinling" and discuss its translations by different translators.

\section{（4）请君试问东流水, 别意与之谁短长?}

Zhao: East flowing water, may I ask you why?

Why is your flow not longer than my sigh?

Xu: Oh! ask the river flowing to the east, I pray,

If he is happier to go than I to stay!

Obata: Pray ask the river, which is the longer of the two -

Its east-flowing stream, or the thoughts of ours at parting?

Alley: (and as I go I tell them to look at the great river swirling eastward,) asking them can it possibly flow further than the love of true friends. 
As one of Li Bai's farewell poetry (送别诗), “Farewell at a Tavern in Jinling" describes a scene that the poet bids farewell to his friends at a tavern in Jinling before he leaves for Yangzhou (扬州). To show the unwillingness to farewell to the friends, the conceptual metaphor "SADNESS IS SCALE" is adopted by the poet. In this conceptual metaphor, the image schema SCALE serves as the source domain, while the abstract concept "SADNESS" is regarded as the target domain, indicating a man's sadness is longer than the endless flowing water. From the above translations, we can find that in translating the metaphor, all the translators translate the two domains but there are some differences in their translations: first, both Zhao and Obata retain the original metaphor in which the length of the flowing water is used to measure the duration of sadness; then, $\mathrm{Xu}$ converts the original metaphor mostly for rhyme. Although his translation "happier to go than I to stay" literally seems to be not related to sadness, we might as well have a look at its another form "sadder to stay than I to go" which is connected with what we are talking about. According to this new expression, "to stay" means the flowing water can't flow and will become dead water in the end, and "to go" means "to leave". Thus, the form "sadder to stay than I to go" can become the form "sadder to lose life than I to leave". That is to say, Xu's real intention is to suggest that leaving is sadder than losing one's life. As he expresses the sadness of the poet indirectly, the target language reader seems to have difficulties in understanding it. As for Alley's translation, we can see the target domain in the original is changed into "love" in the translation. Why does Alley do this? First, the sadness in the poem "Farewell at a Tavern in Jinling" refers to the unwillingness to farewell to the friends, indicating the love of friends. Then, according to the metaphor "LOVE IS A JOURNEY", the PATH schema is mapped onto love and love has the starting point, path and the endpoint. As the flowing water also has its path, it's reasonable to relate love to water. We can notice that Alley converted the original metaphor in his translation.

\section{Conclusion}

As sadness metaphor constitutes an important part of Li Bai's poetry, this paper analyzes its different forms and metaphorical meanings in Li's poems and then conducts a comparative study of different translations including the metrical ones and the free verse ones under the guidance of Conceptual Metaphor Theory and Image Schema Theory. We can find that sensory image schemas and the SCALE schema are often used as the source domains in sadness metaphors although they don't belong to common image schemas held by many scholars. Then, these two types of image schemas are basically reproduced in translation, which shows the similarity in image schemas between Chinese culture and foreign culture. At last, according to the above analyses of the translations, we can conclude that in the process of translating sadness metaphors, the translators tend to adopt the strategies of retaining the original metaphor, converting the original metaphor and paraphrasing the original metaphor in different situations.

1) Although Chinese and English are different, and they are rooted in different cultures, there still exists common cognitive basis. Therefore, we can find corresponding expressions in English with the same or similar metaphorical meanings in C-E 
translation. If both source domains and target domains are the same, the original metaphor can be retained.

2) As there are many differences between two cultural cognitions, literal translation is inappropriate sometimes. In this way, the original metaphor can be converted to narrow the gap between the translation and the target language reader. In addition, if the metaphor is unique in the source language culture, the strategy of paraphrasing the original metaphor can be adopted.

On the basis of these findings, the authors hope more researchers who are interested in Li Bai's poetry and its translation can be involved in researches from the perspective of cognitive linguistics.

\section{References}

Alley, Rewi (1980). Li Pai: 200 Selected Poems. Hongkong: Joint Publishing Co., 44, 86, 180, 193. Feng, Quangong \& Li Lin (2017). On Emotional Metaphors in Classical Chinese Poems and Their English Translations. Language and Translation, (03):57-64.

Johnson, M. (1987). The Body in the Mind: The Bodily Basis of Meaning, Imagination, and Reason. Chicago: University of Chicago Press.

Kövecses, Z. (2000). Metaphor and Emotion: Language, Culture and Body in Human Feeling. Cambridge: Cambridge University Press.

Lakoff, G. \& Johnson, M. (1980). Metaphors We Live by. Chicago: University of Chicago Press. Obata, Shigeyoshi (1922). The Works of Li Po, New York: Dutton, 86, 113, 140,155.

Wang, Feng (2015). A Comprehensive Study on the English Translation of Classical Tang Poetry. Beijing: China Social Sciences Press, 86.

$\mathrm{Wu}, \mathrm{Ni}$ (2013). The Strategy and Translation on Emotion Metaphors of "qi" from the English Version of a Dream of Red Mansions. Journal of West Anhui University, 29(06): 62-64.

Xu, Yuanchong (trans.) (2007). Selected Poems of Li Bai. Changsha: Hunan People's Publishing House, 29, 43, 63, 67.

Yue, Haoping \& Liao Shijun (2009). Study on Cognition and Translation of Emotional Metaphors in English and Chinese. Journal of Changsha University of Science E Technology (Social Sciences), 24(01): 101-103.

Zhang, Chenchen \& Cao Jing (2017). Cognitive System and C-E Translation of Emotional Metaphor Taking "Love" in Three Sisters. Journal of Chongqing Jiaotong University (Social Sciences Edition), 17(03):135-139.

Zhang, Rong (2010). Analysis of Fear Metaphor Translation in The Water Margin. Journal of Inner Mongolia Agricultural University (Social Science Edition), 12(04): 368-369+379.

Zhao, Yanchun (trans.) A Complete English Translation of Li Bai's Poetry. unpublished. 
Creative Commons licensing terms

Author(s) will retain the copyright of their published articles agreeing that a Creative Commons Attribution 4.0 International License (CC BY 4.0) terms will be applied to their work. Under the terms of this license, no permission is required from the author(s) or publisher for members of the community to copy, distribute, transmit or adapt the article content, providing a proper, prominent and unambiguous attribution to the authors in a manner that makes clear that the materials are being reused under permission of a Creative Commons License. Views, opinions and conclusions expressed in this research article are views, opinions and conclusions of the author(s). and European Journal of Literature, Language and Linguistics Studies shall not be responsible or answerable for any loss, damage or liability caused in relation to/arising out of conflicts of interest, copyright violations and inappropriate or inaccurate use of any kind content related or integrated into the research work. All the published works are meeting the Open Access Publishing requirements and can be freely accessed, shared, modified, distributed and used in educational, commercial and non-commercial purposes under a Creative Commons Attribution 4.0 International License (CC BY 4.0). 